10IKC-184

\title{
AGE CONSTRAINTS ON ULTRA-DEEP MANTLE PETROLOGY SHOWN BY JUINA DIAMONDS
}

\author{
M.T. Hutchison ${ }^{1}$, C.W. Dale ${ }^{2}$, G.M. Nowell ${ }^{2}$, F.A. Laiginhas ${ }^{2}$ and D.G. Pearson ${ }^{3}$ \\ 1. Trigon GeoServices Ltd., 2780 S. Jones Blvd., \#35-15, Las Vegas, NV 89146, U.S.A. email: mth@trigon-gs.com \\ 2. University of Durham, U.K. 3. Department of Earth \& Atmospheric Sciences, University of Alberta, Edmonton, Canada
}

\section{INTRODUCTION}

Diamonds from Juina, Brazil represent the most prolific locality for ultra-deep sourced diamonds known (Hutchison, 1997; Harte et al., 1999). Syngenetic mineral inclusion parageneses coupled with high pressure and temperature experiments (Gasparik and Hutchison, 2000; Walter et al., 2011), supported by mineral and diamond host chemistry, crystallography and retained internal pressure reveal origins for Juina diamonds from the Earth's Transition Zone and Lower Mantle. Variations amongst Juina diamonds reflect a complex stratigraphy incorporating subducted crust over a range of depths (Bulanova et al., 2010; Walter et al., 2011). Of particular importance to the understanding of mantle evolution is that Juina diamonds indicate a chemical distinction between Upper and Lower Mantle (Hutchison et al., 2001) where Transition Zone diamonds are variable but typically more eclogitic in character whereas Lower Mantle diamonds are consistently primitive and peridotitic. These chemical differences suggest separate convection between the Upper and Lower Mantles at least during the bulk of the time period of Juina diamond formation. In order to fully understand the significance of the mantle cross-section Juina diamonds provide, it must be placed in the context of geological time.

Kimberlites hosting Juina diamonds are Cretaceous and a Cretaceous age ( $101 \pm 7 \mathrm{Ma}$ ) has been acquired from in-situ U$\mathrm{Pb}$ dating of a single $\mathrm{Ca}$-silicate inclusion (Bulanova et al., 2010). This age, which is almost contemporaneous with kimberlite eruption is surprising as the bulk of Juina diamonds show complex growth histories, cubic forms are absent, and as discussed in the following, the high degree of nitrogen aggregation despite its low abundance all point to considerable mantle residence.

The most robust age determinations of diamonds arguably come from analyses of whole, single crystal sulphide inclusions. Sulphides are the most dominant mineral group residing as inclusions within diamonds world-wide (e.g. Gurney et al., 1979) and usually have an intimate, cogenetic association with diamonds and the C-N-O-S melts from which they are interpreted to have formed (Haggerty, 1986). Sulphide inclusions are rare however within Juina diamonds, the most common phase being $(\mathrm{Mg}, \mathrm{Fe}) \mathrm{O}$ (ferropericlase). This deviation from the norm possibly reflects a loss of sulphide from subducting slabs penetrating the Transition Zone and certainly implies a considerably different fluid composition involved in diamond formation, particularly within the Lower Mantle. Whilst rare, sulphides are still present in Juina diamonds, being reported by Hutchison (1997), Hayman et al. (2005) and Bulanova et al. (2010) and hence potential exists to determine a robust formation age from Re-Os systematics.

Here we report the results of a program of breakage of Juina diamonds targeting the dark-coloured inclusion suite with the first Re-Os model age determination from the deep mantle. The suite of Juina diamonds studied were recovered from alluvial terraces of the Rio Vinte e Um de Abril immediately downstream from kimberlite pipe Aripuanã-01 and within the locality termed 'Property 1000 '. The sampling location lies in UTM Zone $21 \mathrm{~L}$ at WGS84 $(262540,8707130) \pm 50 \mathrm{~m}$.

\section{METHODOLOGIES}

\section{DIAMOND MEASUREMENT AND INCLUSION RECOVERY}

The diamonds were weighed and their appearances carefully described and documented. $\mathrm{N}$ concentration and aggregation was measured using Trigon GeoServices Ltd.'s Thermo-Nicolet Avatar 360 fourier-transform infra-red spectrometer (FTIR) fitted with a $\mathrm{KBr}$ beam-splitter and $4 \mathrm{x}$ beam condenser. Spectra were obtained at a resolution of $1 \mathrm{~cm}^{-1}$ and were deconvoluted using software provided by D. Fisher (DTC). Diamond crystals were carefully broken using a purpose-built steel anvil following the methodology described in Hutchison et al. (2004).

\section{INCLUSION CHEMISTRY / METHODOLOGY ASSUMPTIONS}

The visual appearance of released inclusions were described and documented and their dimensions measured using the Univ. of Durham's Hitachi TM-1000 Tabletop scanning electron microscope (SEM). Mineral chemistry was determined semi-quantitatively using the energy-dispersive spectrometry (EDS) functionality of the same instrument.

The recovered sulphide was dissolved and Re and Os separated for analyses using an ultra-clean technique described by Pearson et al. (1998). After Os micro-distillation, Re was removed by micro-anion exchange at which point other PGEs were also separated. Osmium elemental and isotopic concentrations were determined by negative thermal ionisation mass spectrometry (N-TIMS) using the University of Durham's Triton mass spectrometer. Rhenium and other PGEs were analysed at Durham on a Thermo Electron Element 2 magnetic sector ICPMS using methods described in Dale et al. (2009).

The high ionisation efficiency of Os using -ve ion emission and relatively high Re and Os contents in sulphides allow the analysis of single grains. Ideally a $\mathrm{Re}-\mathrm{Os}$ isochron age would be acquired to assess disturbances in the isotopic system. However even single sulphide Re-Os model ages are preferable to composite methods such as are applied to $\mathrm{Sm}-\mathrm{Nd}$ systematics, which are

Extended Abstract 


\section{$10^{\text {th }}$ International Kimberlite Conference-2012}

necessarily constructed without assurance that the grains are in equilibrium, and ion microprobe methods such $\mathrm{U} / \mathrm{Pb}$ in silicates where considerable matrix related fractionation effects are unquantified. This latter method was used in the determination of a Mesozoic age for Juina diamond JU1 (Bulanova et al., 2010).

Re-Os fractionation during development of mono-sulphide solid solution typical in inclusions in diamonds is likely to be high, hence it is critical that the whole inclusion is measured. This rules out laser ablation approaches. However, extracting the whole inclusion carefully and analysis in bulk by dissolution mitigates against this effect. In fact Re-Os fractionation provides a benefit whereby multiple sulphides available within the same diamond have a high potential for producing a robust, single diamond geochron (Pearson et al., 1998). The drawback of the Re-Os model age approach, which is necessary where only single sulphides are available, is the assumption of a single stage evolutionary history and the additional assumption that the sulphide was extracted from a reservoir with Bulk Earth-like or chondritic isotopic composition. Considerable uncertainty regarding the isotopic evolution of $\mathrm{Os}$ in the mantle exists. Whilst some peridotitic (p-type) isochrons indicate a chondritic initial ratio (Pearson et al., 1998) others have produced moderately radiogenic initial Os isotope ratios (Westurlund et al., 2006; Aulbach et al., 2011) which increase the possible uncertainties on the model ages by 200-300 Ma. There is significantly greater uncertainty for model ages in eclogitic (etype) sulfide inclusions because e-type sulfide Re-Os isochrons typically have very radiogenic initial ratios (e.g., Pearson et al., 1998; Richardson et al., 2001). Given these caveats, and that only a single sulphide inclusion was recovered in the current study, the resulting age can only be interpreted in a model age framework. However, as Juina diamonds have likely formed over a significant period of time, it is considered most critical to ascertain which Geological Era the snapshot of mantle convection and stratigraphy the Juina diamonds reflect, rather than a precise age.

\section{RESULTS}

\section{METALLIC INCLUSIONS}

Visual inspection of Juina samples revealed a number of stones containing inclusions surrounded by black halos commonly seen around sulphide inclusions (Harris, 1992). Six diamond crystals were chosen and broken. One diamond, discussed in the following section revealed a sulphide. Of the remaining five stones, four revealed a total of nine inclusions of $\mathrm{Ni}, \mathrm{Cr}-\mathrm{Fe}$ alloy. The number of inclusions recovered matches those initially observed within the diamonds as recoverable. No other inclusions of comparable size were identified within the broken diamond residues. With one exception, the $\mathrm{Ni}, \mathrm{Cr}-\mathrm{Fe}$ grains have a maximum dimension greater than $100 \mu \mathrm{m}$ and the largest grain recovered, JUz12C, was measured at $200 \times 180 \times 160 \mu \mathrm{m}$. Most grains have a reasonably distinct crystal form but often with a slightly irregular and sometimes curved surface and internal fabric. Grains are metallic and either black or slightly golden, dark grey. Fifteen analyses were conducted by EDS with averages presented in Table 1. There is little compositional difference between grains, which provide an average of $\mathrm{Ni}_{9} \mathrm{Cr}_{19} \mathrm{Fe}_{72}$.

Whilst the recovery of metallic grains matches clear observations made before breakage and analyses are only semi-quantitative, their compositions show an unnerving similarity to the steel used in the crushing process, Table 1 .
Table 1 Compositions of metallic inclusions and crusher steel

\begin{tabular}{|r|r|r|r|r|r|r|r|r|r|r|}
\hline & $\mathbf{z 4 B}$ & $\mathbf{z 4 C}$ & $\mathbf{z 1 2 A}$ & $\mathbf{z 1 2 B}$ & $\mathbf{z 1 2 C}$ & $\mathbf{z 1 4 A}$ & $\mathbf{z 1 4 B}$ & $\mathbf{z 1 3 A}$ & $\mathbf{C R}-D a$ & $\mathbf{C R}-D o$ \\
\hline$\#$ & 2 & 1 & 3 & 1 & 3 & 1 & 1 & 2 & 2 & 2 \\
\hline $\mathbf{C r}$ & 19.1 & 20.9 & 19.9 & 21.8 & 19.7 & 20.8 & 19.2 & 16.9 & 22.7 & 19.6 \\
\hline $\mathbf{F e}$ & 70.5 & 70.9 & 70.5 & 71.8 & 71.0 & 70.6 & 72.5 & 75.4 & 73.2 & 69.7 \\
\hline $\mathbf{N i}$ & 10.5 & 8.2 & 9.7 & 6.3 & 9.2 & 8.6 & 8.4 & 7.7 & 4.1 & 10.8 \\
\hline
\end{tabular}

$\mathrm{Ni}, \mathrm{Cr}$ and $\mathrm{Fe}$ data are all normalised to a combined total of $100 \mathrm{wt} \%$. Sample numbers are prefixed by 'JU'. \# :- number of analyses contributing to average; Cr-Da:- Durham crusher base anvil steel; Cr-Do:- Durham crusher body steel.

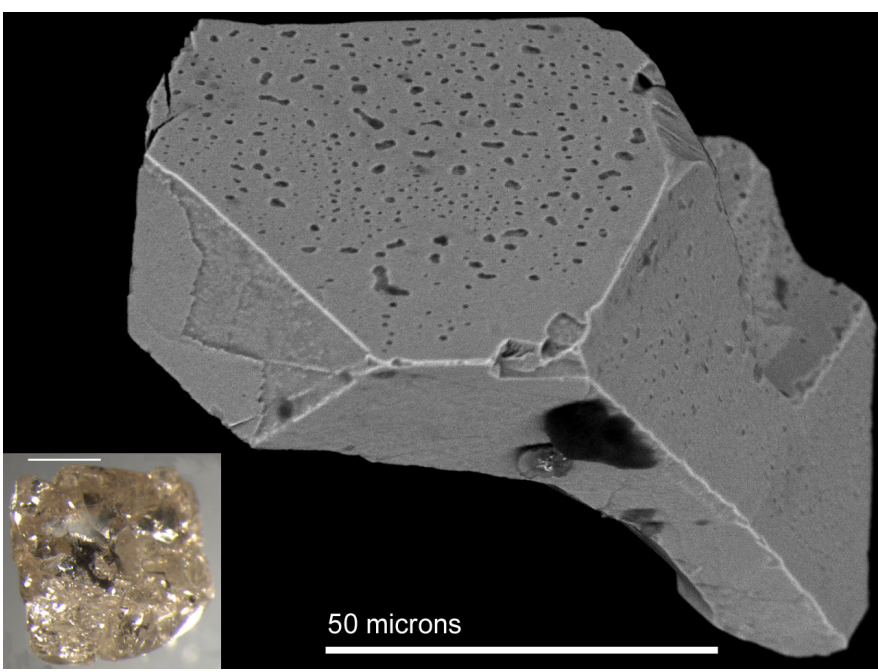

Fig. 1 Pyrrhotite inclusion JUc26A. Grayscale image is a secondary electron SEM image showing imposed diamond morphology on the sulphide crystal faces. Crystal size is $\sim 115 \times 75 \times 52 \mu \mathrm{m}$. The colour inset is of the host diamond with internal reflections from the dark sulphide evident in the central part of the stone. The inset scale-bar represents $1 \mathrm{~mm}$.

\section{SULPHIDE INCLUSION JUC26A}

Diamond crystal JUc26 was light brown with some patches of stronger orange colouration (Fig. 1) and weighed $15.6 \mathrm{mg}$. It was heavily pitted and irregular but with relict dodecahedral morphology. Moderate plastic deformation was evident on visual inspection and the stone was typical of Juina diamonds. Infra-red spectrometry showed the diamond to be Type IIa, poor in nitrogen. A single, black inclusion was evident in the centre of the stone with no evidence of associated surfacereaching fractures. On crushing, a single sulphide inclusion, JUc26A, was recovered in-tact (Fig. 1). The grain had a dark, dull, golden colouration typical of pyrrhotite and showed clear crystal faces of imposed diamond morphology (Fig. 1) confirming a syngenetic origin with its diamond host. The inclusion was weighed ten times on a micro-balance averaging $0.885 \pm 0.135 \mu \mathrm{g}$, and close to the limit which can be analysed with Re-Os systematics (Pearson and Shirey, 1999).

Inclusion JUc26A was analysed by EDS, 6 analyses with pyrrhotite stoichiometry average $\left(\mathrm{Fe}_{0.84} \mathrm{Ni}_{0.16}\right)_{0.93} \mathrm{~S}$ (Table 2). Measurements of $\mathrm{Ni}$ in JUc26A range from $5.0-15.3 \mathrm{wt} \%$. As $\mathrm{Cu}$ was not resolved in EDS measurements but is present up to $\sim 2 \mathrm{wt} \%$ in more precisely measured Juina inclusions (Table 2 ), it is likely also present in JUc26A. Hence the Ni content of 


\section{$10^{\text {th }}$ International Kimberlite Conference-2012}

JUc26A may be modestly over-estimated. PGE concentrations are provided in Table 3 where Os and Re were present in similar quantities (196 and $260 \mathrm{ppb}$ respectively). ${ }^{187} \mathrm{Re} /{ }^{188} \mathrm{Os}$ was determined to be 6.49 and the ${ }^{187} \mathrm{Os} /{ }^{188} \mathrm{Os}$ ratio is 0.2581 \pm 0.0026 , providing a single-crystal model age of $1271 \pm 89 \mathrm{Ma}$ indicating formation in the Mesoproterozoic. The quoted uncertainty propagates only the analytical uncertainties and does not account for the potential range of initial ratios.

Table 2 Compositions of Juina sulphides

\begin{tabular}{|l|r|r|r|r|r|r|r|}
\hline & JUc26A & BZ215A & BZ221 A2 & BZ222A & BZ222B & BZ222C & BZ231A \\
\hline $\mathbf{A v *}$ & 6 & 1 & 1 & 1 & 1 & 1 & 3 \\
\hline $\mathbf{F e}$ & 51.62 & 57.37 & 56.48 & 60.39 & 60.54 & 58.06 & 62.79 \\
\hline $\mathbf{C r}$ & 0.10 & n.a. & n.a. & n.a. & n.a. & n.a. & n.a. \\
\hline $\mathbf{C o}$ & n.a. & 0.43 & 0.37 & 0.30 & 0.32 & 0.28 & 0.00 \\
\hline $\mathbf{N i}$ & 10.20 & 3.38 & 4.33 & 1.61 & 1.61 & 1.38 & 0.14 \\
\hline $\mathbf{C u}$ & n.a. & 1.93 & 0.61 & 0.97 & 1.28 & 1.43 & 0.13 \\
\hline $\mathbf{Z n}$ & n.a. & 0.07 & 0.00 & 0.03 & 0.03 & 0.06 & 0.03 \\
\hline $\mathbf{S}$ & 37.93 & 36.14 & 36.46 & 35.69 & 35.33 & 35.32 & 36.50 \\
\hline Tot & $\mathbf{9 9 . 8 5}$ & $\mathbf{9 9 . 3 3}$ & $\mathbf{9 8 . 2 6}$ & $\mathbf{9 8 . 9 8}$ & $\mathbf{9 9 . 1 0}$ & $\mathbf{9 6 . 5 4}$ & $\mathbf{9 9 . 5 9}$ \\
\hline
\end{tabular}

Analyses in wt\%. *:- number of analyses contributing to average; n.a.:- not analysed. BZ-prefixed sulphides determined by WDS (Hutchison, 1997).

Table 3 Re-Os-Pt measurements of Juina sulphide JUc26A

\begin{tabular}{|r|r|r|r|r|r|r|}
\hline Pt ppb & Re ppb & Os ppb & ${ }^{187} \mathbf{R e} /{ }^{188} \mathbf{O s}$ & ${ }^{187} \mathbf{O s} /{ }^{188} \mathbf{O s}$ & $\gamma \mathbf{O s}$ & T MA \\
\hline 30520 & 260 & 196 & 6.49 & 0.2581 & 101.2 & 1271 \\
\hline 31000 & 278 & 203 & 6.72 & 0.2607 & & 1182 \\
\hline 29880 & 234 & 188 & 6.09 & 0.2555 & & 1360 \\
\hline
\end{tabular}

Numbers in italics are upper and lower error ranges. T MA:- model age in Ma.

\section{DISCUSSION}

\section{METALLIC INCLUSIONS}

Native iron inclusions in diamonds have been reported previously. Sobolev et al. (1981) for example report native iron and sulphide in Yakutian diamonds. From Juina, Bulanova et al. (2010) report native Fe in Collier 4 samples co-existing with majoritic garnet and Hayman et al. (2005) report native iron with eclogitic pyrrhotite. No published works however address the possibility of contamination from the steel crushers used in inclusion release which always generate significant spall into broken diamond residues. Kaminsky and Wirth (2011) who note the presence of nanometer-scale smears of native iron in Juina diamonds and also Fe-C-(N) phases similarly do not address the possibility of contamination nor in this case do they address the possibility of epigenetic growth along apparent fractures within their samples. An early study of Juina diamonds (Hutchison, 1997) reported a candidate $\mathrm{Fe}$ inclusion (BZ208A) however precision WDS analyses revealed no significant compositional differences within the capability of the instrument between the 'inclusion' and the crusher steel (Table 4). The visual identification of inclusions in the diamonds of this study, their morphology and large size, and the absence of other inclusions in the residue is compelling evidence to support the described $\mathrm{Ni}, \mathrm{Cr}-\mathrm{Fe}$ grains as being genuine inclusions. However without serious consideration of the possibilities of contamination involving trace element analyses for this and other publications claiming native iron inclusions, the jury is still out on the occurrence of this phase as a syngenetic inclusion in diamond when recovered by diamond breakage. If further work determined that the Ni,Cr$\mathrm{Fe}$ grains in this study were genuine inclusions, their large size and recovery in-tact provides strong potential for isotope and trace element study.

Table 4 High-precision crusher steel / candidate inclusion analyses from Juina diamond BZ208

\begin{tabular}{|l|c|c|c|c|c|c|c|}
\hline & $\mathbf{S i}$ & $\mathbf{C r}$ & $\mathbf{F e}$ & $\mathbf{N i}$ & $\mathbf{M n}$ & $\mathbf{C o}$ & TOT \\
\hline Cr-E & 0.24 & 0.46 & 96.62 & 0.12 & 0.28 & 0.15 & 97.87 \\
\hline BZ208A & 0.25 & 0.46 & 96.68 & 0.09 & 0.3 & 0.17 & 97.96 \\
\hline
\end{tabular}

Analyses determined by high precision WDS-EPMA.. Cr-E:- Edinburgh crusher steel. All data from Hutchison (1997).

\section{SULPHIDE INCLUSION}

Classification of sulphide paragenesis is best conducted using coexisting silicate inclusions. In their absence, such as for JUc26A, sulphide mineral chemistry is used. Pearson and Shirey (1999) quote a typical concentration of $\sim 50 \mathrm{ppb}$ for Os in e-type sulphide, Re in both p-type and e-type sulphide, and $\sim 5,000 \mathrm{ppb}$ Os in p-type sulphide. Bulanova et al. (1996) favour a $12 \% \mathrm{Ni}$ cutoff with e-type sulphides lying below the threshold and with a transitional field interpreted to be associated with a pyroxenitic paragenesis. Isotopically, low $\mathrm{Ni}$ sulphides have radiogenic Os (positive $\gamma \mathrm{Os}$ ) whereas high $\mathrm{Ni}$ sulphides tend to be equal to or below present-day bulk Earth compositions (Pearson and Shirey, 1999). Classifications are still debated and furthermore it is not clear how these criteria would apply to Juina sulphides as Transition Zone and Lower Mantle-derived inclusions have not previously been measured for PGEs. However following the above definitions and comparing with data from Siberian, South African and Canadian samples (Fig. 2), the compositions of JUc26A satisfy the criteria as being derived from an eclogitic paragenesis. Notwithstanding the possible over-estimate in $\mathrm{Ni}$ content, if the average Ni concentration determined correctly reflects the bulk composition of the sulphide, JUc26a lies close to the boundary of the e-type sulphides with those of a peridotitic association. Hence, inclusion JUc26A may derive from a bulk composition which is dominantly ecolgitic but also indicates significant mixing with a peridotitic component. This interpretation is consistent with JUc26A being derived from subducted crust at great depth where significant dilution from peridotitic bulk mantle has occurred. Such a reservoir may be expected to have an initial Os isotopic ratio only moderately elevated above chondrite.

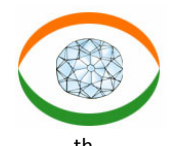




\section{$10^{\text {th }}$ International Kimberlite Conference-2012}
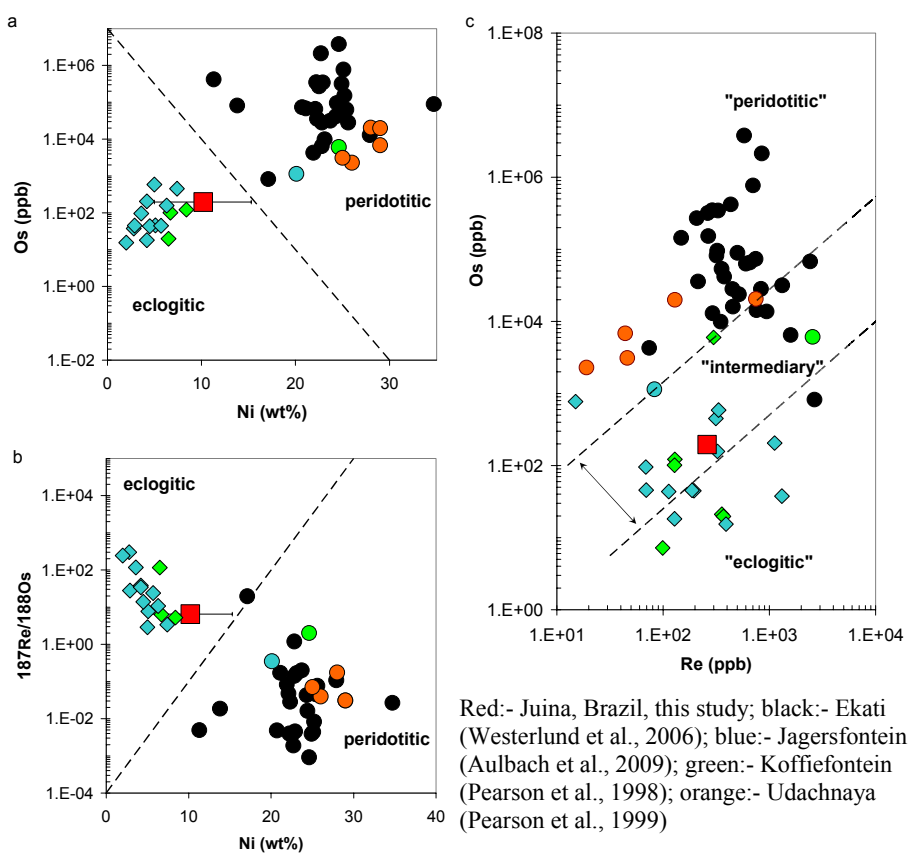

Red:- Juina, Brazil, this study; black:- Ekati (Westerlund et al., 2006); blue:- Jagersfontein (Aulbach et al., 2009); green:- Koffiefontein (Pearson et al., 1998); orange:- Udachnaya (Pearson et al., 1999)

Fig. 2 Compositions of JUc26A in the context of worldwide sulphide inclusions in diamonds. Colours follow the key. Circles :inclusions described as peridotitic; diamonds :- inclusions described as eclogitic; square :- JUc26a where solid line represents the range of $\mathrm{Ni}$ concentrations measured in the inclusion; $a$. and $b$. discriminatory boundaries of Westerlund et al. (2006) are not based on geochemical criteria but serve to divide eclogitic from peridotitic sulphides as determined by mineral associations and other criteria. c. of Aulbach et al. (2009) are average eclogitic and peridotitic ratios based on Pearson \& Shirey (1999) data.

Compared to other Juina sulphides, the composition of JUc26A is rather more Ni-rich than those from the majority of alluvial diamonds from Hutchison (1997, Table 2) and from the Collier 4 pipe (Bulanova et al., 2010). However the composition does fall within the range reported by Hayman et al. (2005) who report both a low-Ni suite $(<3.6 \mathrm{wt} \%)$ and a sulphide with $35 \mathrm{wt} \% \mathrm{Ni}$. Bulanova et al. (2010) report sulphide as part of an association of CaTiSi-perovskite, garnet and $\mathrm{SiO}_{2}$ (their 'Group 2') with intermediary $\mathrm{d}^{13} \mathrm{C}$ interpreted to have a deep Transition Zone origin with a component of subducted oceanic crust. This association appears to correspond to Hayman et al.'s (2005) paragenesis 'C' with perovskite and $\mathrm{Ca}$-Si-perovskite interpreted to have an origin $>580 \mathrm{~km}$ in depth. Hutchison et al. (1999) reports $\mathrm{d}^{13} \mathrm{C}$ of sulphide-hosting diamonds in the range -5 to $-12 \%$ which errs moderately more towards the typical lower mantle value of 5\% (Hutchison et al., 1999) than Bulanova et al.'s range of 12 to $-15 \%$ and consistent with JUc26a having a significant ptype component. In general terms though, the body of evidence supports Juina sulphide-hosting diamonds being derived from the deeper reaches of the Transition Zone.

The calculated Mesoproterozoic age of $1271 \mathrm{Ma}$ assumes a chondritic initial ratio for inclusion JUc26A. Given the uncertainty in the initial Os isotopic ratio for eclogite, it is instructive to test the effect this may have on the model age. Unless the initial Os isotopic ratio of the parental reservoir is greater than 0.22 , i.e. very close to the measured ratio, then the formation age of the sulphide must be at least 290 Ma prior to kimberlite eruption and is a maximum of $1271 \mathrm{Ma}$ if the initial Os isotope ratio is broadly chondritic. If the $\mathrm{Re} / \mathrm{Os}$ ratio is also increased above a chondritic ratio, the minimum formation age becomes older. Hence at the youngest extreme of the model, data from JUc26a indicate a significantly greater age than the Mesozoic age no more than 16.5 Ma prior to kimberlite emplacement reported (for a separate sample) by Bulanova et al. (2010). As discussed previously, it is not likely that the end-member high initial Os ratio tested applies and hence a Proterozoic age for JUc26a is preferred. Multiple diamond formation ages from single kimberlites are known. For example at Koffiefontein, Pearson et al. (1998) reported high Os and high $\mathrm{Ni}(24 \%)$ p-type sulphides giving a two inclusion isochron consistent with contemporaneous formation of sulphide and kimberlite and e-type sulphides from other diamonds defining ages of $\sim 1.1 \mathrm{Ga}$ and $\sim 2.7 \mathrm{Ga}$, i.e., much older than kimberlite emplacement. Sulphide (and hence diamond) formation ages that are significantly older than the age of kimberlite eruption are the norm in most studies (e.g., Richardson et al., 2001; Aulbach et al., 2009; 2011). The aggregation of nitrogen within the diamond lattice can be measured and proceeds at a known rate between $\mathrm{IaA}$ and $\mathrm{IaB}$ (Taylor et al., 1990). Pearson et al.'s (1998) inclusion ages are consistent with the nitrogen component of their diamond hosts. The kimberlite-contemporaneous diamonds are completely unaggregated (less than 1\% IaB) despite concentrations of $250 \mathrm{ppm} \mathrm{N}$. In contrast, Koffiefontein diamonds with $\sim 980$ Ma residence times were aggregated up to $38 \% \mathrm{IaB}$. Other examples of diamonds contemporaneous with kimberlite emplacement based on nitrogen data exist: Hutchison and Heaman (2008) calculate $<1$ Ma residence time before eruption for Sarfartoq diamonds, W. Greenland. Sarfartoq diamonds are very N-rich, which should easily aggregate to $\mathrm{IaB}$ and yet the $\mathrm{IaB}$ components are small, hence residence times must be very short. This situation however is the opposite of what is known from Juina diamonds which are usually very nitrogen poor and as such, long residence times combined with high temperatures are required to aggregate nitrogen. However in addition to being nitrogen-poor, Juina diamonds are almost always very highly aggregated and always in cases where nitrogen contents are low but measurable (Hutchison et al. 1999). Long residence times, extremely high temperatures or a combination of both are hence required to explain the typical $\mathrm{N}$ characteristics of Juina diamonds. Certainly deep mantle temperatures can be high and in the case of Bulanova et al.'s (2010) JU1 it can be tested whether they are high enough for the residence times they quote. Using the methodology of Taylor et al. (1990), an estimate of $99 \%$ aggregation with a conservative upper estimate of $10 \mathrm{ppm} \mathrm{N}$ (JU1 nitrogen is reported as below

Extended Abstract 


\section{$10^{\text {th }}$ International Kimberlite Conference-2012}

detection limit but associated diamonds are reported as highly aggregated) and finally an upper error residence time of 16.5 Ma, JU1 must have experienced a minimum average temperature of $1536^{\circ} \mathrm{C}$. This temperature is reasonable for the maximum pressure of origin of $20 \mathrm{GPa}$ cited by Bulanova et al. (2010). However JU1 would have had to have resided at 20 GPa for the full duration from formation to eruption which is inconsistent with the cooler temperature experienced in a subducting slab and the re-equilibration event cited by Bulanova et al. (2010) at much cooler $200 \mathrm{~km}(\sim 7 \mathrm{GPa})$ depth.

Nitrogen concentration and aggregation as a means to estimate mantle residence time is fraught by the strong influence of often poorly constrained temperature. Multi-stage residence at anomalously high temperature and late-stage growth capturing young inclusions not reflected by the bulk nitrogen properties of the host diamonds could still account for a genuine young age for some Juina inclusions. However in the case of JUc26a, where various reservoir models provide precise residence times, as a cross-check, $\mathrm{N}$ characteristics can provide accurate estimates of main residence temperatures. JUc26a has some absorption due to $\mathrm{N}$ in its infra-red spectrum and whilst a precise measurement cannot be made, comparing Juina stones measured with the same analytical procedure the $\mathrm{N}$ concentration of JUc26a is not likely to exceed $5 \mathrm{ppm}$. A 5 $\mathrm{ppm} \mathrm{N}$ diamond aggregated to $99 \% \mathrm{IaB}$ with a residence time of $1178 \mathrm{Ma}$ (using our calculated $1271 \mathrm{Ma}$ age and Heaman et al.'s (1998) emplacement age of $93.1 \mathrm{Ma}$ ) gives a minimum average temperature of $1403^{\circ} \mathrm{C}$ which translates to a residence pressure of $\sim 12 \mathrm{GPa}$ following a geotherm averaged from Jeanloz and Richter (1979) and Solheim and Peltier (1993). This gives much more scope for deep Transition Zone formation and a complex history involving subducting slab temperatures than an age contemporaneous to eruption allows. So whilst uncertainties in the source reservoir composition introduce considerable uncertainty on the formation age for JUc26A, the chondritic Mesoproterozoic model age is consistent with the inclusion chemistry, host diamond chemistry and typical Juina diamond characteristics,. Further work identifying additional sulphides is expected to clarify the reservoir conditions and considerably further reduce uncertainty on formation age.

\section{SUMMARY AND CONCLUSIONS}

Despite observation pre-breakage, as for prior study of possible metallic inclusions (Hutchison, 1997), analyses of nine $\sim \mathrm{Ni}_{9} \mathrm{Cr}_{19} \mathrm{Fe}_{72}$ grains apparently released from five Juina diamonds could not satisfactorily distinguish 'inclusion' chemistry from steel components of equipment routinely used to break diamonds. This study whilst potentially identifying large $\mathrm{Fe}$ inclusions, establishes the critical need for all reports of $\mathrm{Fe}$ and $\mathrm{Fe}$-alloy inclusions in diamond to be accompanied by assessment of the composition of preparation equipment.
A single sulphide, JUc26A of composition $\left(\mathrm{Fe}_{0.84} \mathrm{Ni}_{0.16}\right)_{0.93} \mathrm{~S}$ gave a Re-Os chondritic model age of 1271 Ma. Poor constraints on eclogite reservoir composition apply considerable uncertainty to the actual formation age however most generous estimates of a minimum age involving little mixing of chondritic mantle with a crustal component place the minimum formation of JUc26A some hundreds of Ma before kimberlite emplacement. PGE compositions have JUc26A residing within the peridotitic end of a dominantly eclogitic compositional field. PGE data and comparison with other sulphide-bearing diamonds from Juina supports JUc26A being derived from the deep Transition Zone (below $\sim 580 \mathrm{~km}$ ) within an environment of significant dilution of subducted slab amongst bulk peridotitic-pyrolitic mantle. Hence the initial reservoir relevant to JUc26A may not be as extreme as the young end-member quoted above. Evidence for complex growth history and host diamond nitrogen compositions are consistent with considerable mantle residence involving formation at Transition Zone depths and some exposure to the cooler temperatures typical in subducting slabs. Conversely, the nitrogen characteristics of Juina diamonds are not generally consistent with formation contemporaneous with kimberlite emplacement as suggested elsewhere. The balance of evidence from the current study supports placing the mantle stratigraphy and separate upper and lower mantle convection supported by Juina diamonds in the Proterozoic.

\section{REFERENCES}

Aulbach, S. et al. (2009) Cont. Mineral. Petrol. 157, 525-540.

Aulbach, S. et al. (2011) Cont. Mineral. Petrol. DOI 10.1007/s00410-0100573-4

Bulanova, G.P. et al. (1996) Cont. Mineral. Petrol. 124, 111-125

Bulanova, G.P. et al. (2010) Cont. Mineral. Petrol. 160, 489-510

Dale, C.W. et al. (2009) Geochim. Cosmochim. Acta. 73, 1394-1415

Gasparik, T. \& Hutchison, M.T. (2000) Earth Planet. Sci. Letts., 181, 103-114

Gurney, J.J. et al. (1979) In. Boyd, F.R. and Meyer, H.O.A. eds. Kimberlites, diatremes and diamonds. AGU, Washington, 1-15

Haggerty, S.E. (1986) Nature, 320, 34-38

Harris, J.W. (1992) In: Field, J.E. ed. The properties of natural and synthetic diamond. Academic Press, London. 325-393

Harte, B. et al. (1999) Geochem. Soc. Spec. Pub. 6, 125-153.

Hayman, P.C. et al. (2005) Cont. Mineral. Petrol. 149, 430-445

Heaman, L. et al. (1998) In: Ext. Abs., 7th Int. Kimberlite Conf., Cape Town, $322-324$

Hutchison, M.T. (1997) Ph.D. thesis, Univ. Edinburgh, pp. 660. CD-ROM

Hutchison, M.T. \& Heaman, L.M. (2008) Canad. Mineral. 46, 1063-1078

Hutchison, M.T. et al. (1999) In: Gurney, J.J. et al. eds. Proc. VIIth Int. Kimberlite Conf., Vol. I. Red Roof Design, Cape Town 372-382

Hutchison, M.T. et al. (2001) Cont. Mineral. Petrol. 142, 119-126

Hutchison, M.T. et al. (2004) Lithos 77, 273-286

Jeanloz, R. \& Richter, F. (1979) J. Geophys. Res. 84 B10, 5497-5504

Kaminsky, F.V. \& Wirth (2011) Canad. Mineral. 49, 555-572

Pearson, D.G. \& Shirey, S.B. (1999) Rev. Econ. Geol., 12, 143-171

Pearson, D.G. et al. (1998) Earth Planet. Sci. Letts. 160, 311-326

Pearson, D.G. et al. (1999) Geochim. Cosmochim. Acta, 5, 703-711

Richardson, S.H. et al. (2001) Earth Planet Sci Lett. 191:257-266

Sobolev, N.V. et al. (1981) Geologika i Geofizica 12, 25-29

Solheim, L. \& Peltier, W. (1992) Can. J. Earth Sci. 30, 881-892

Taylor, W.R. et al. (1990) Am. Mineral. 75, 1290-1320.

Walter, M.J. et al. (2011) Science, 334, 54-57

Westerlund, K.J. et al. (2006) Cont. Mineral. Petrol., 152, 275-29

Extended Abstract

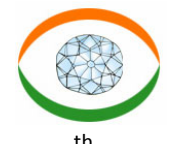

